\title{
LANDASAN PENYUSUNAN PROGRAM PEMBELAJARAN MATEMATIKA BAGI SISWA TUNAGRAHITA RINGAN
}

\author{
D Devita ${ }^{1, a}$, D Desmayanasari ${ }^{2, b}$ \\ ${ }^{1}$ Pendidikan Luar Biasa, FKIP, Universitas Muhammadiyah Lampung \\ ${ }^{2}$ Pendidikan Matematika, FKIP, Universitas MuhammadiyahLampung, \\ Jl. H. Zainal Abidin Pagar Alam No.14 Bandar Lampung \\ e-mail: ${ }^{a}$ deladevita02@gmail.com, bdwisesmayana@gmail.com
}

\begin{abstract}
Mentally retarded children or also called children with intellectual disability are children with below average intelligence who experience obstacles in adaptive behavior in the form of taking care of themselves and carrying out activities of daily living. Children with intellectual disability need special education and services to help them achieve optimal development. Children with mild intellectual disability require three basic skills, such as reading, speaking and arithmetic. The implementation of learning in the classroom, especially in learning mathematics requires learning modifications, so that they are in accordance with the individual conditions of intellectual disability students. Intellectual disability students have obstacles to think about something abstract, so in the preparation of learning programs the teacher is expected to; (1) understanding the characteristics of mild intellectual disability students, (2) conducting assessments, (3) being creative in modifying learning methods.
\end{abstract}

Keywords : intellectual disability, mathematics, learning programs

\begin{abstract}
Abstrak
Anak tunagrahita atau disebut juga anak dengan hambatan intelektual merupakan anak dengan kecerdasan di bawah rata-rata yang mengalami hambatan pada perilaku adaptif yaitu keterampilan dalam bina diri. Anak tunagrahita memerlukan Pendidikan dan layanan yang khusus untuk membantu mereka mencapai perkembangan yang optimal. Anak tunagrahita ringan memerlukan tiga kemampuan dasar, seperti membaca, berbicara dan berhitung. Pelaksanaan pembelajaran di kelas terutama pada pembelajaran matematika memerlukan modifikasi pembelajaran, sehingga sesuai dengan kondisi individu siswa tunagrahita. Siswa tunagrahita memiliki hambatan untuk berfikir sesuatu yang abstrak, maka dalam penyusunan program pembelajaran diharapkan guru; (1) memahami karakteristik siswa tunagrahita ringan, (2) Melakukan Asesmen, (3) kreatif dalam memodifkasi metode pembelajaran.
\end{abstract}

Kata kunci : hambatan Intelektual, tunagrahita, matematika, program pembelajaran 


\section{PENDAHULUAN}

Pendidikan merupakan hak setiap individu sebagai warga negara seperti yang diamanatkan dalam UUD pasal 31, termasuk di dalamnya adalah hak pendidikan bagi anak berkebutuhan khusus. Pelaksanaan pendidikaan bagi anak yang berkebutuhan khusus tentu berbeda dengan anak pada umumnya, diperlukan perencanaan yang matang terkait dengan pendekatan dan strategi pembelajaran khusus yang digunakan agar menghasilkan pendidikan yang optimal. Guru perlu merencankan serta menyusun program pembelajaran yang sesuai dengan kemampuan juga kebutuhan siswa, berdasarkan pada karakteristik dan kondisi masing-masing individu anak berkebutuhan khusus.

Pengembangan pendekatan pembelajaran untuk anak yang berkebutuhan khusus perlu memperhatikan prinsip-prinsip sebagai berikut; (1) prinsip kasih sayang, (2) prinsip layanan individual, (3) prinsip kesiapan, (4) prinsip keperagaan, (5) prinsip motivasi, (6) prinsip belajar dan bekerja kelompok, (7) prinsip keterampilan, (8) prinsip penanaman dan penyempurnaan sikap (Efendi, 2008) [5]. Prinsip-prinsip tersebut juga menjadi perhatian bagi praktisi Pendidikan dalam Menyusun program pembelajaran untuk siswa yang berkebutuhan khusus, begitupun dengan siswa tunagrahita.

Anak tunagrahita merupakan anak yang memiliki tingkat kecerdasan yang rendah, sehingga membutuhkan Pendidikan dan layanan khusus dalam menjalankan tugas perkembangannya. Pendidikan bagi ABK terutama anak tunagrahita memerlukan perencanaan yang baik dalam penyusunan program pembelajaran, tidak terkecuali pada pembelajaran matematika. Sebelum Menyusun program pembelajaran sebaiknya guru mengetahui kelemahan, kekuatan serta kebutuhan siswa terkait dengan pembelajaran matematika yang diperoleh dari analisis hasil asesmen. Sehingga 


\section{Hipotenusa}

Journal of Research Mathematics Education VOL.4 NO.2 2021

pembelajaran dapat disesuaikan dengan kemampuan serta kebutuhan siswa. Berdasarkan hal tersebut maka penulis rasa perlu untuk membahas apa saja yang perlu diperhatikan dalam perencanaan penyusunan program pembelajaran matematika bagi siswa tunagrahita ringan, sehingga dapat membantu praktisi Pendidikan dalam melayani anak berkebutuhan khusus terutama siswa tunagrahita di sekolah.

\section{PEMBAHASAN}

\section{Terminologi Tunagrahita}

Istilah Tunagrahita berasal dari bahasa Sansekerta tuna yang artinya rugi, rusak; dan grahita artinya berfikir, memahami atau mengerti. Tunagrahita menurut Kamus Besar Bahasa Indonesia [4] adalah cacat pikiran; lemah daya tangkap; dan keterbelakangan mental. "Tunagrahita atau keterbelakangan mental merupakan kondisi di mana perkembangan kecerdasannya mengalami hambatan sehingga tidak mencapai tahap perkembangan yang optimal [10]".

Terminologi intellectual disability untuk anak yang memiliki keterbelakangan mental dan intelektual sudah banyak mengalami perubahan dan perkembangan dalam penyebutannya, seperti yang dijelaskan [8]

"There have been many changes in the way people with an intellectual disability have been named and categorised. Terms formerly used such as idiot, imbecile, feebleminded, mentally subnormal, moron, mentally deficient and retard are now seen as highly pejorative and stigmatising, although at the time of their use they were acceptable terms in the scientific literature. Likewise, organisations have responded to use more contemporary acceptable language. Examples are the AAIDD (formerly the American Association on Mental Retardation and, earlier, the American Association on Mental Deficiency), the International Association for the Scientific Study of Intellectual Disabilities (also, formerly "Mental Deficiency") and Inclusion International (formerly International League of Societies for Persons with a Mental Handicap)".

[8] menyatakan bahwa, mengubah nilai-nilai dan sikap sosial dapat memengaruhi makna literal dan definisional. Ada beberapa alasan yang mendasari perubahan terminologi tersebut, hal ini 
disampaikan oleh [9] "The term intellectual disability is increasingly being used instead of mental retardation because of following reasons; (1) Reflects the change construct of disability described by the AAIDD and WHO; (2) Aligns better with current professionals practices that focus on functional behavior and contextual factors; (3) Is less offensive to persons with disability; (4) Is more consistent with international terminology".

American Association on Intellectual and Developmental Disabilities [1], mendefinisikan hambatan intelektual adalah disabilitas (hambatan) ditandai dengan keterbatasan yang signifikan dalam fungsi intelektual dan perilaku adaptif, mencakup keterampilan sosial dan kegiatan sehari-hari, disabilitas ini terjadi sebelum usia 22 tahun.

AAIDD memaparkan tiga kriteria seseorang dianggap memiliki hambatan intelektual [1]

1. Fungsi intelektual di bawah rata-rata: yang merujuk pada kapasitas mental secara umum seperti; belajar, penalaran, pemecahan masalah, dll. Salah satu cara mengukur fungsi intelektual adalah dengan tes IQ.

2. Keterbatasan signifikan perilaku adaptif. Seperti Keterampilan konseptual bahasa dan literasi; konsep uang, waktu, serta angka; juga pengarahan diri. Keterampilan sosial, keterampilan interpersonal, tanggung jawab sosial, harga diri, mudah tertipu, kenaifan (yaitu, kewaspadaan), pemecahan masalah sosial, dan kemampuan untuk mengikuti aturan/mematuhi hukum dan menghindari menjadi korban. Keterampilan praktis dalam aktivitas kehidupan sehari-hari (perawatan pribadi), keterampilan bekerja, perawatan kesehatan, perjalanan/transportasi, jadwal/rutinitas, keselamatan, cara mengunakan uang, penggunaan telepon dll.

3. Kondisi ini merupakan salah satu dari beberapa disabilitas (hambatan) perkembangan. yang terbukti dengan adanya disabilitas (hambatan) selama periode perkembangan, yang diidentifikasi sebelum usia 22 tahun.

Berdasarkan pemaparan di atas, disimpulkan bahwa tunagrahita 


\section{Hipotenusa}

Journal of Research Mathematics Education

disebut juga hambatan intelektual (intellectual disability) adalah merupakan istilah yang digunakan untuk seseorang individu yang memiliki kecerdasan dibawah rata-rata yang disertai dengan hambatan pada perilaku adaptif, hal tersebut terjadi pada masa perkembangan sebelum usia 22 tahun.

\section{Klasifikasi Anak Tunagrahita Ringan}

Ada tiga klasifikasi untuk anak tunagrahita. Umumnya pengelompokan ini di dasarkan pada kemampuan intelegensinya, yaitu (1) tunagrahita ringan, (2) tunagrahita sedang dan (3) tunagrahita berat.[10] menyatakan, kemampuan intelegensi anak tunagrahita kebanyakan diukur menggunakan tes Stanford Binet dan Skala Weschler (WISC).

1. Tunagrahita Ringan

Menurut Binet kelompok ini memiliki IQ antara 68-52, dan memiliki IQ 69-55 berdasarkan Skala Weschler. Dengan pendidikan dan bimbingan yang baik, anak tunagrahita ringan dapat belajar membaca, menulis dan berhitung sederhana.

2. Tunagrahita Sedang

Pada Skala Binet kelompok ini memiliki IQ 51-36 dan 54-40 berdasarkan Skala Weschler. Anak tunagrahita sedang bisa dilatih untuk pengembangan diri dan mengoptimalkan kemampuan perilaku adaptifnya, seperti merawat diri dan melindungi diri.

3. Tunagrahita Berat

Menurut Skala Binet, kelompok ini memiliki IQ antara 32-20 dan IQ antara 39-25 menurut Skala Weschler. Anak tunagrahita berat memerlukan perawatan secara menyeluruh, baik dalam hal mengurus diri dan memerlukan perlindungan dari bahaya sepanjang hidupnya.

Dari tiga klasifikasi diatas, hanya kelompok anak tunagrahita ringan yang dapat mengikuti pembelajaran terutama matematika. [3] menyatakan bahwa anak tunagrahita (Intellectual Disability), setidaknya harus memiliki; (1) kemampuan dasar dalam hal literesi, numeresi dan keterampilan berkomukasi lisan, (2) keterampilan 
perilaku adaptif (personal living skill-social living skills).

3. Pembelajaran Matematika bagi Anak Tunagrahita Ringan

Anak tunagrahita memiliki hambatan dalam hal memahami yang abstrak, salah satu contohnya seperti pemahaman terhadap simbolsimbol yang mewakili suatu konsep tertentu dalam matematika. [11] menyatakan bahwa "science education, regarding students with intellectual disability, could involve a combination of teacher-directed and student-directed learning practices, considering, in any case, information about the learning and behavioral characteristics of the individual student. Information based on the appropriate assessment of the student's difficulties and competencies could be utilized in specifying the necessary adaptations or modifications during the learning process". Maka, untuk mencapai kompetensi yang diharapkan sebaiknya guru melakukan perencanaan penyusunan program pembelajaran dengan mempertimbangkan hal-hal berikut.

a. Karakteristik Peserta Didik

Anak tunagrahita memiliki karakteristik yang unik. [5] menyatakan bahwa beberapa hambatan tampak pada anak tunagrahita pada segi kognitif juga sekaligus menjadi karakteristiknya adalah; (1) cenderung berfikir konkret, (2) sulit berkonsentrasi, (3) hambatan dalam bersosialisasi, (4) sulit memahami instruksi yang kompleks, (5) kurang memiliki kemampuan menganalisis dan menilai kejadian yang dihadapi. Maka dari itu, penting kiranya bagi guru untuk memahami karakteristik tersebut agar dapat Menyusun sebuah program pembelajaran yang dapat mendukung tercapainya pembelajaran yang optimal.

b. Asesmen

"Assessment is a systematic process of gathering information in order to make appropriate educational decisions for a student. It is a progressive process identifying the student's strengths and needs, and results in the design and implementation of selected educational strategies. Assessments can vary and include both 
formal and informal processes which involve observing the child in the classroom or school yard, assessing a child's reading, spelling or maths skills and finding out about the general level of ability" [7].

Sebelum Menyusun program pembelajaran matematika sebaiknya guru melakukan asesmen akademik. Asesmen dilakukan untuk mengetahui tingkat kemampuan (pemahaman) dan hambatan tertentu dalam sebuah materi pembelajaran. Analisis hasil asesmen juga dapat mengetahui kebutuhan siswa dalam mencapai target pembelajaran yang diharapkan.

c. Metode Pembelajaran

Menurut [2] model pembelajaran merupakan prosedur atau pola sistematis yang digunakan sebagai pedoman untuk mencapai tujuan pembelajaran yang di dalamnya terdapat strategi, teknik, metode, bahan, media dan alat penilaian pembelajaran. Sedangkan metode pembelajaran adalah cara atau tahapan yang digunakan dalam interaksi antara peserta didik dan pendidik untuk mencapai tujuan pembelajaran yang telah ditetapkan sesuai dengan materi dan mekanisme metode pembelajaran.

[6] menyatakan bahwa guru harus memiliki metode yang tepat untuk mengajar anak dengan hambatan intelektual. Metode yang tepat akan membantu siswa memahami materi yang diberikan. Guru dapat memanfaatkan teknologi dengan menggunakan media pembelajaran seperti gambar dan video melalui alat elektronik seperti tablet, smartphone, dan computer dalam membantu siswa berfikir konkret sehingga pembelajaran menjadi lebih efektif. Maka dalam memberikan pembelajaran matematika untuk siswa tunagrahita diharapkan guru mampu memadu padankan model pembelajaran dan mengkolaborasikan antara metode pembelajaran satu dengan lainnya 


\section{KESIMPULAN}

Berdasarkan literatur yang telah dipaparkan, maka dapat disimpulkan bahwa dalam Menyusun sebuah program pembelajaran matematika untuk anak tunagrahita ringan guru perlu; (1) memahami karakteristik siswa tunagrahita, (2) melakukan asesmen untuk mengetahui kemampuan, hambatan dan kebutuhan siswa tunagrahita, (3) memanfaatkan teknologi dalam mengkolaborasi model pembelajaran dan memodifikasi metode pembelajaran.

\section{DAFTAR PUSTAKA}

[1] AAIDD. (2021). American Association on Intellectual and Developmental Disabilities AAIDD. Retrieved from AAIDD: https://www.aaidd.org/intellectual-disability/definition

[2] Afandi, M., Chamalah, E., \& Wardani, O. P. (2013). Model Dan Metode Pembelajaran Di Sekolah. In Perpustakaan Nasional Katalog Dalam Terbitan (KDT) (Vol. 392, Issue 2). https://doi.org/10.1007/s00423-006-0143-4

[3] Alimin, Z. (2011). Model Pembelajaran Anak Tunagrahita (Intellectual Disability) Melalui Pendekatan Konseling (Penelitian Tindakan Kolaboratif dalam Upaya mengembangkan Anak Tunagrahita Mencapai Perkembangan Optimum). Jassi Anakku, 10(2), 165-175.

[4] Badan Pengembangan dan Pembinaan Bahasa, Kementerian Pendidikan, Kebudayaan, Riset, dan Teknologi Republik Indonesia. (2021, September 2). KBBI Daring. Retrieved from kbbi.kemdikbud.go.id:

https://kbbi.kemdikbud.go.id/entri/tunagrahita

[5] Efendi, M. (2008). Pengantar Psikopedagogik Anak Berkelainan. Jakarta: PT Bumi Aksara.

[6] Kim Jiu, C., Zulfia, N., Dwi Rahayu, I., \& Jhoni Putra, G. (2020). Students with Intellectual Disability in Special Needs School: A Qualitative Study. International Journal of Multidisciplinary Research and Publications Intellectual Disability in Special Needs School: A Qualitative Study, International Journal of Multidisciplinary Research and Publications (IJMRAP), 2(12), 57-60. 
[7] National Council For Special Education. (2006). www.ncse.ie. Retrieved from ncse.ie: https://ncse.ie/wpcontent/uploads/2014/10/final_report.pdf

[8] Parmenter, T. R. (2011). What is intellectual disability? how is it assessed and classified? International Journal of Disability, Development and Education, 58(3), 303-319. https://doi.org/10.1080/1034912X.2011.598675

[9] Shree, A., \& Shukla, P. C. (2016). Intellectual Disability: Definition, classification, causes and characteristics. Learning Community-An International Journal of Educational and Social Development, 7(1), 9. https://doi.org/10.5958/2231-458x.2016.00002.6

[10] Somantri, T. S. (2012). Psikologi Anak Luar Biasa. Bandung: PT Refika Aditama.

[11] Stavroussi, P., Papalexopoulos, P., \& Vavougios, D. (2010). Science Education and Students With Intellectual Disability: Teaching Approaches and Implications. Problems of Education in the 21st Century, 19, 103-112. 